By K. N. V. PALMER, M.D.(Camb.), M.R.C.P.(Lond.)
Senior Lecturer in Medicine, University of Aberdeen

Pulmonary complications after operation still remain a common and often serious complication in the surgical patient despite extensive investigation of their mechanism and treatment.

The common post-operative pulmonary abnormality is the development of segmental atelectasis; less commonly atelectasis involving the lobe of a lung or the whole lung occurs. Atelectatic areas in the lung readily become infected leading to a patchy bronchopneumonia and it is often only when bronchopneumonic changes have supervened that the patient complains of respiratory symptoms. Atelectasis results from the retention in the lungs of viscous bronchial secretions which occlude bronchi with the subsequent absorption of air from the area of lung involved (Coryllos, 1929 and 1930). The prevention and treatment of this condition therefore depends upon the recognition of the factors which cause the retention of sputum in the lungs after operation (Palmer and Sellick, 1953).

The main mechanisms which are responsible for the retention of sputum in patients after operation are: (I) a deficient expulsive mechanism, (2) a reduction in bronchial calibre, and (3) qualitative or quantitative changes in the bronchial secretion. All these factors are probably involved in the majority of patients who develop pulmonary complications after operations, but occasionally one may be predominant. Atelectasis has occurred during operations (Cassells and Rapoport, 1944), and these cases are probably due to reflex bronchoconstriction.

(1) Deficient Expulsive Mechanism. Excess bronchial secretion is normally removed from the larger bronchi by the cough reflex (Ballon, 1939; Bullowa, 1944), but secretion in the smaller bronchi is normally moved by the activity of the ciliated bronchial epithelium (Jackson and Jackson, 1933; Boyd et al., 1943). After operations pain from the wound, reduced diaphragmatic movement (Howkins, 1944), tight abdominal binders and opiates restrict coughing, while anaesthetics, anoxia, carbon dioxide excess and changes in the viscosity of the bronchial secretion reduce ciliarys activity (Hill, 1928; Negus, 1933). Thus, the normal mechanism for the removal of secretion from large and small bronchi is seriously deranged $\vec{\omega}$ following operations.

(2) Reduction in Bronchial Calibre. Congestion of the bronchial mucosa and bronchial spasmo reduce bronchial calibre. Bronchial spasm may윽 occur in the induction period if an endotrachealtube is introduced into an insufficiently anaesthetized patient, and when anaesthetics such as? cyclopropane (Rovenstine, 1942) and barbiturates (Burnstein and Rovenstine, 1938) are used. It $\vec{c}$ may be caused during the operation throug of rough handling of the viscera and traction on the mesentery (De Takats et al., 1942), or after to operation if there is severe pain (Lucas, 1950). Congestion of the bronchial mucosa may be pro-⿳亠二口 duced by irritant anaesthetic vapours or by aspiration of irritant material into the lungs. The $\stackrel{\mathbb{Q}}{\circ}$ inhalation of stomach contents may follow vomit- $\overrightarrow{\vec{B}}$ ing which is obvious to the anaesthetist, but silent 3 regurgitation may occur which may not be noticed $\mathcal{}$ until the mask is removed at the end of the operation (Culver et al., I95 I).

When there is congestion or spasm of the 3 . bronchi, very small amounts of secretion may produce bronchial occlusion and atelectasis.

(3) Changes in Bronchial Secretion. The amount $ᄋ$ of bronchial secretion is increased by infection and $₹$ irritation of the bronchi and by stimulation of the 의 secretory glands of the bronchi reflexly via the $\rightarrow$ vagus (Florey et al., 1932; De Takats et al., 1942). The viscosity of the bronchial secretion $N$ is increased in dehydration, chronic bronchitis and when large doses of atropine (Thomas et al., $\stackrel{N}{\circ}$ r938), scopolamine (Hibima and Curreri, 1942) or $\underset{\omega}{ }$ pethedine (Blanschard, 1954) are given. This is an important factor in the production of atelec- 0 tasis, for when the viscosity of the bronchial $\varnothing$ secretion is increased, ciliary movement is reduced $\stackrel{\mathcal{P}}{\rightarrow}$ and stagnation of secretion occurs in the smaller 0 bronchi.

There are, therefore, many factors involved in 
TABLE I

Incidence of Pulmonary Complications Following Abdominal Operations

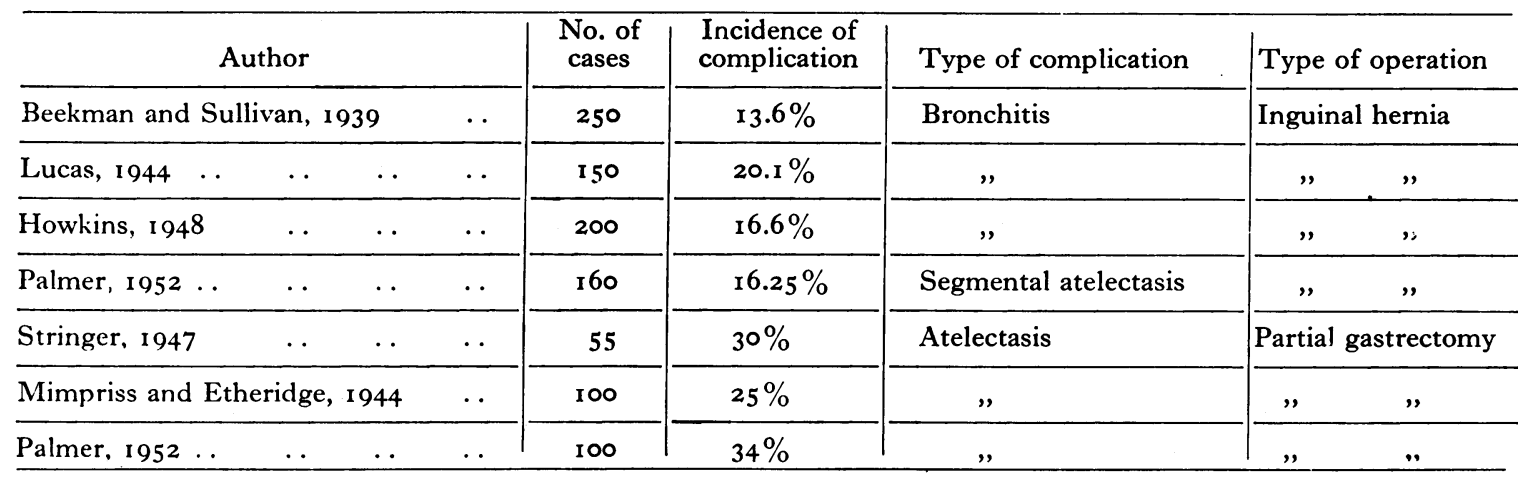

the production of post-operative atelectasis. All act eventually by causing the retention of sputum, which in turn leads to atelectasis and bronchopneumonia.

\section{The Incidence}

The definition of chest complications in the literature varies considerably from author to author. Most writers consider a productive cough after operation to be evidence of a chest complication, but unless routine radiographs of the chest are taken it is difficult to be sure that segmental atelectasis is not present. In a personal series of 260 cases where clinical and radiological examinations of the chest were made before, and at daily intervals after the operation, the incidence of atelectasis diagnosed radiologically was $26 / 160$ ( 16.25 per cent.) in a group of patients undergoing operation for repair of inguinal hernia, and 34/100 (34 per cent.) in a group who were undergoing partial gastrectomy for chronic peptic ulcer. The lesion was commonly basal and unilateral, but it was bilateral in I6.6 per cent. of cases. There were three cases of lobar atelectasis (3 per cent.), all of which occurred in cases after partial gastrectomy. These figures are similar to the findings of others (Table I).

\section{Factors Affecting the Incidence}

\section{The Operation}

Chest complications are especially common after abdominal procedures particularly those in the upper abdomen such as gastrectomy, cholecystectomy and operations for the repair of inguinal hernia. King (1933) showed that of 3,037 operations upon the abdomen, including operations for the repair of inguinal hernia, 13 per cent. were followed by chest complications, whereas of 4,028 operations on other parts of the body only I per cent. was thus complicated. King remarked that this incidence after laparotomy and hernia repair was so definite that for the purpose of analysis other operations could be disregarded. Atelectasis is uncommon after gynaecological operations, but pulmonary embolism is relatively common.

The surgeon may unwittingly predispose a patient to $\mathrm{d}$ ivelop these complications by causing reflex bronchoconstriction and the secretion of sticky mucus through traction on the mesentery and abdominal viscera, if the surgery is not as gentle as possible.

\section{Age and Sex}

These complications are, in general, much commoner in men than women, and there is also a definite increase with advancing years (Palmer, I952).

\section{Time of Year}

Griffith (1934) considered chest complications to be commoner in the first three months of the year, when the incidence of respiratory tract infection is highest. Other workers, however, have been unable to find any definite increase in the winter months (Brunn and Brill, 1930; King, 1933; Brock, I936; Stringer, 1947; Palmer, 1952). It has been suggested that in dry weather the bronchial secretion may be reduced in amount and become more viscid, thus causing a greater liability to chest complications (Brock, 1936).

\section{Smoking and Bronchitis}

Smokers taking ten cigarettes or half an ounce of tobacco a day are six times more liable to develop chest complications after operations than non-smokers (Morton, 1974). During the late war it was found that Service patients were more prone to develop these complications than civilians (Bird et al., r913). This may be due to heavy smoking which is common in the Service, and to the high incidence of upper respiratory tract 
TABLE 2

Incidence of Bronchitis in Patients Who Developed

Post-operative Pulmonary Complications

\begin{tabular}{|c|c|c|c|c|c|}
\hline \multirow[b]{3}{*}{ History of bronchitis } & \multirow[b]{3}{*}{$\ldots$} & \multicolumn{2}{|c|}{$\begin{array}{l}\text { Group with chest } \\
\text { complications } \\
60\end{array}$} & \multicolumn{2}{|c|}{$\begin{array}{c}\text { Group without chest } \\
\text { complications } \\
200\end{array}$} \\
\hline & & No. & $\%$ & No. & $\%$ \\
\hline & & 39 & 65 & 71 & $35 \cdot 5$ \\
\hline Clinical evidence of bronchitis & .. & 20 & $33 \cdot 3$ & 18 & 9.0 \\
\hline Radiological evidence of bronchitis & . . & 18 & 30.0 & I3 & 6.5 \\
\hline
\end{tabular}

infections which occur under barrack conditions. Smoking is of importance because it is an important factor in the development of bronchitis (Palmer, I954), but unless bronchitis is present, even a heavy smoker is not necessarily a high risk case (Palmer, 1952). Table 2 shows the incidence of bronchitis pre-operatively in a consecutive group of 260 patients who were undergoing abdominal operations. It can be seen that the incidence of bronchitis is much higher in the group who developed chest complications than in those who did not. Bronchitis is of importance because these patients readily produce a viscid bronchial secretion and bronchospasm, and it is the most important single factor which predisposes the patient to the development of chest complications after operation.

The diagnosis of minimal degrees of bronchitis is often difficult, especially if the patient is seen in the summer months. If a patient confesses to a recurrent productive winter cough which lasts a fortnight or more, some respiratory damage is likely to be present, and he should be considered a high risk case, even though there is no other evidence of chest disease. If a patient has a demonstrable productive cough before operation, the diagnosis of bronchitis presents little difficulty. In the absence of a productive cough, rhonchi are the best guide to the presence of bronchitis, and when this sign is present the patient must be considered a high risk case. Râles are found on routine examination of the chest very commonly, but a careful assessment is necessary before a diagnosis of bronchitis is justified on this finding alone. If there are showers of moist râles which are brought out by coughing, there is probably some secretion in the smaller bronchi, and a diagnosis of bronchitis is justified. But fine dry râles which clear readily on coughing may be safely disregarded.

A radiological diagnosis of bronchitis is of value in assessing the liability of a patient to develop chest complications after operation. Table 2 shows that a radiological diagnosis of bronchitis was made in 30 per'cent. of the cases who de--o veloped chest complications, but in only 6.5 per 3 cent. of those who were not so complicated. Ideally a chest radiograph should always be $\frac{\omega}{\omega}$ taken in patients about to undergo a majoror surgical procedure in order to exclude the $\vec{i}$ presence of unsuspected pulmonary tuberculosis.

\section{Type of Anaesthetic}

Inhalation anaesthesia is not an important cause ฏ of post-operative pulmonary complications, for complications occur as frequently when spinal or local anesthesia are used (Mikulicz, r901 ; King, $\vec{\varphi}$ 1933; Griffith, 1934; Dawkins, 1936).

Methods of anaesthesia which produce under ventilation of the lung for long periods may produce patchy basal atelectasis (Swank and Smedel, I948). Cyclopropane is not ideal for high risk cases as it is given in a closed circuit with a high concentration of oxygen, and as these $\stackrel{\mathbb{Q}}{\square}$ gases are absorbed rapidly into the blood, the $\overrightarrow{\overrightarrow{0}}$ alveoli collapse readily if there is secretion 3 occluding a bronchus (Dale and Rahn, 1952; Sellick, 1952). Cyclopropane also depresses respiration and as Rovenstine (1942) has shown it을 can cause bronchospasm and an increase in 3 bronchial secretion. Muscle relaxants which render the oesophageal sphincters atonic predispose to the aspiration of stomach contents into the lungs, so that these drugs should be used with cuffed endotracheal tubes and only after gastric음 aspiration (Postgrad. Med. F., I952).

Chloroform and trilene have the advantage of being non-irritant to the respiratory tract, but $N$ chloroform is too toxic and trilene too weak to provide adequate anaesthesia for major surgery (Lucas, 1950). Large doses of atropine after $\omega$ operation have been incriminated as a cause of chest complications by increasing the viscosity of $\bullet$

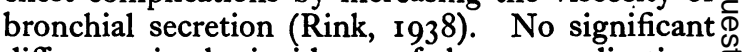
difference in the incidence of these complications ? could be demonstrated, however, when premedi- $\frac{T}{0}$ cation with omnopon and scopolamine or atropine $\frac{O}{\mathbb{D}}$ and morphine was used (Morton, I944). Pethe- $\frac{\rho}{\mathbb{Q}}$ 
dine is being used increasingly for premedication. It has the advantage of preventing bronchial spasm, especially that due to thiopentone (Sellick, I952), but has the disadvantage of being a depressant to the respiratory centre, of increasing the viscosity of the bronchial secretion (Blanschard, 1954) and it does not relax mental tension as efficiently as the derivatives of morphine.

There is insufficient evidence to incriminate any particular method of anaesthesia as an important cause of post-operative pulmonary complications. Deep anaesthesia should be avoided, drugs which may increase bronchial spasm should be used with caution, and great care should be taken to prevent the aspiration of material into the lungs from the stomach or upper respiratory tract.

\section{Clinical Features \\ Bronchitis}

A slight increase in bronchial secretion after operation does not constitute a deviation from normal. A productive cough with minimal systemic upset occurs frequently, but a diagnosis of simple bronchitis should not be made too readily, for if a radiograph of the chest is taken in all cases, the incidence of significant abnormalities is found to be high.

\section{Segmental Atelectasis}

This is the common form of chest complication. It is normally basal and unilateral but may involve segments in the right middle lobe or lingula. It usually occurs during the first $24-48$ hours after operation; but in the early stages there is little or no constitutional disturbance. Productive cough and pyrexia do not usually appear until infection supervenes. The clinical diagnosis is often difficult at this stage for diminished air entry at the bases is found in all patients who have had an abdominal operation, but sonorous rhonchi at the bases, or more generally throughout the lung fields, are found much more frequently in the first day after operation in those who develop atelectasis than in those who do not, and this is a most valuable early physical sign (Palmer, 1952). Once the condition is established there is impairment of percussion note, areas of bronchial breathing with increased voice conduction and areas of absent breath sounds. The signs often change dramatically after a bout of coughing. The condition usually clears up in a week or so, but it may be complicated by bronchopneumonia, pleural effusion and bronchiectasis (Morle and Robertson, I953) if early effective treatment is not instituted.

\section{Massive Collapse of the Lung}

In this condition there is collapse of a whole lung or the lobe of a lung. The clinical onset is usually sudden with a feeling of tightness or an ache in the lower part of the chest and praecordium. Dyspnoea which may be severe follows, and the patient often appears cyanosed and ill. Cough with a viscid mucoid sputum usually develops within a few hours, the pulse and respiratory rate are markedly increased and the temperature may be raised to $103^{\circ} \mathrm{F}$. or more.

Examination of the chest reveals diminished or absent movement on the affected side and there is marked shift of the mediastinum towards the side of the lesion as shown by displacement of the trachea and apex beat. The percussion note is dull, the breath sounds-are absent or diminished, or there may be tubular breath sounds with bronchophony and whistling pectoriloquy. High pitched rhonchi may be heard over the affected side.

\section{Differential Diagnosis}

Cases of massive collapse with the sudden onset of dramatic symptoms have to be distinguished from lobar pneumonia, pulmonary embolism, pneumothorax, cardiac infarction or the perforation of a hollow viscus. The position of the mediastinum is often the deciding factor, and a portable chest radiograph and the electrocardiograph give additional information.

Pulmonary embolism usually occurs about ten? days after the operation, but may occur at any time. The clinical features vary considerably, depending upon the size of the embolus and the suddenness of the occlusion. A large pulmonary embolus may cause death very rapidly. With smaller emboli, sudden dyspnoea, a constricting pain over the praecordium (which seldom goes into the arms) and cyanosis are found. On examination there are tachycardia and an increase in jugular venous pressure, and a proto-diastolic triple rhythm may be heard over the sternum. Emboli are usually formed from a thrombus in the deep veins of the leg or pelvis, and tenderness in the calf, and pain on dorsiflexion of the foot (Homans, 1943) may be present. Frequently a rise in temperature and pulse rate, due to the underlying phlebothrombosis, is observed a few days before the dramatic acute manifestations of pulmonary embolism take place. Changes of acute cor pulmonale may occur in the electrocardiograph, but these are often transient. When infarction of the lung occurs there is fever, pleuriti : pain and haemoptysis, and on examination of the chest, a pleural rub, signs of pleural effusion or consolidation may be discovered. An infarct shadow, pleural reaction or elevation of the diaphragm may be found radiologically (Short, I95I). 
The possibility of pulmonary tuberculosis should be kept in mind in any obscure conditions in the chest which develop after operation, and when abnormal signs are found at the bases of a lung, usually on the right side, the possibility of this being due to a subphrenic collection of pus should be considered.

\section{Treatment}

The aim of treatment is to prevent the formation of bronchial secretion, to assist its removal from the lungs after operation and to prevent infection occurring in an atelectatic portion of the lung. High risk cases must be recognized and treated thoroughly before operation.

To achieve these objects much reliance has been placed on the pre- and post-operative use of antibiotics and breathing exercises. Experience with antibiotics and sulphonamides has proved disappointing in preventing these complications (Lucas, 1944; Holborrow and Spriggs, 1948; Palmer and Sellick, 1952). Prophylactic breathing exercises and penicillin cannot be recommended, for in a controlled experiment no evidence was found that systemic procaine penicillin and breathing exercises given before and after operation, either singly, or in combination, influenced the incidence or severity of pulmonary complications (Palmer and Sellick, 1952).

Whilst penicillin does not prevent these complications it almost certainly does reduce the incidence of the more serious complications after operation. In the late complications one is dealing with a bronchopneumonia due to infection in an atelectatic area of the lung, and pencillin is of value as it is in pneumonic conditions generally. The condition should be recognized and treated, however, before the stage of infection is reached. Breathing exercises fail to prevent these complications because they are not effective in enabling secretion to be coughed up after the operation, and penicillin fails because it does not reduce the viscidity of the sputum (May, 1953).

A regimen which has proved very effective in the prevention and treatment of post-operative atelectasis consists in the pre- and post-operative oral inhalation of $\mathrm{I}$ cc. of $\mathrm{I}$ per cent. solution of isoprenaline (neo-epinine solution No. I B.W.) by means of a hand inhaler followed by $5^{-20}$ minutes' postural drainage. The foot of the bed is raised 18 in., and clapping and vibratory percussion is given to the bases of the lungs in both lateral and prone positions. This regimen is given thrice daily before operation until no sputum can be produced, the last treatment taking place just before the premedication is given. Post-operative inhalations are given di rectly consciousness returns and postural drainage $\bar{z}$ with vibratory and clapping percussion to the chest wall resumed every six hours until no longer. necessary (Palmer and Sellick, 1953).

Steam inhalations in conjunction with iso prenaline and postural drainage are of value whenc the secretion is extremely viscid, because steam reduces the viscosity of the bronchial secretion without increasing its amount (Basch et al., 1944)

\section{BIBLIOGRAPHY}

ANNOTATION (1952), Post. Grad. med. F., 28, 2.

BALLON, H. C. (1939), Amer. Rev. Tuberc., 40, 1.

BASCH, E. P., HOLINGER, P. and PONCHER, H. G. (1941) Amer. F. Dis. Child., 62, 981 .

BEEKMAN, F., and SULLIVAN, J. E. (1939), Surg. Gynec Obstet., 68, 1052.

BIRD, H. M., KILNER, S. D., and MARTIN, D. J. (1943)心 Brit. med. ' F., i, 754.

BLANSCHARD, G. P. (1954), Personal Communication.

BOYD, E. M., PERRY, W. F., STEVENS, M. E. T. (1943) U Amer. F. Physiol., 140, 467.

BROCK, R. C. (1936), Guy's Hosp. Rep., 86, r91.

BRUNN, H., and BRILL, S. (1930), Ann. Surg., 92, 801.

BULLOWA, J. G. M. (1944), Ұ. Mt. Sinai Hosp., ro, 508.

BURNSTEIN, C. L., and ROVENSTINE, E. A. (1938), fPharmacol., 63, 42.

CASSELLS, W. H., and RAPOPORT, A. E. (r944), Anaesthesiology 5,174 .

CORYLlOS, P. N. (1929), F. Amer. med. Ass., 93, 98.

CORYLLOS, P. N. (1930), Surg. Gynec. छீ Obstet., 50, 795.

CULVER, G. A., MAKEL, H. P., and BEECHER, H. K. (19gx) Amer. Surg., 133, 280.

DALE, W. A., and RAHN, H. (1952), Amer. F. Physiol., 170,

DAWKINS, C. J. M. (1936), 'On the Incidence of Anaesthetic Complications and their Relation to Basal Narcosis,' Middlegex Hospital Press, by John Murray, London, W.r. DE TAKATS, G., FENN, G. K. and JENKINSON, E. L. (1942)

FLOREY, H., CARLETON, H. M., and WELLS, A. Q. (1932) Brit. F. exp. Path., 13, 269.

GRIFFITH, H. F. (1934), Brit. F. Anaesth., I1, 89.

HIBMA, O. V., and CURRERI, A. R. (1942), Surg. Gynec. Obstet. 74, 851 .

HILL, L. (1928), Lancet, ii, 802.

HOLBORROW, E. J., and SPRIGGS, E. A. (1948), Lancet, 1i, 688-

HOMANS, J. (1943), New Eng. F. Med., 229, 309.

HOWKINS, J. (1948), Lancet, ii, 85.

JACKSON, C., and JACKSON, C. L. (1933), Amer. F. med. Sci. 186, 849 .

KING, O. S. (1933), Surg. Gynec. Obstet., 56, 43.

LUCAS, B. G. B. (1944), Brit. F. Surg., 31, 288.

LUCAS, B. G. B. (1950), Anaesthesia, 5, 194.

MAY, J. R. (1953), Lancet, ii, 899.

MIKULICZ (190I), Verh. d. dentsch. Gesethsch. F. clin., 30, 560.

MIMPRISS, T. W., and ETHERIDGE, F. G. (1944), Brit. med.

MORLE, K. D. F., and ROBERTSON, P. W. (1953), Brit. med. $\mathcal{F}$. i, 130 .

MORTON, H. J. V. (1944), Lancet, i, 368.

NEGUS, V. E. (1933), Proc. R. soc. Med., 26, ii, 1127.

PALMER, K. N. V. (1952), M.D. Thesis, Cambridge.

PALMER, K. N. V. (1954), Brit. med. F., 1, 1473.

PALMER, K. N. V., and SELLICK, B. A. (1952), Lancet, i, $345 . N$

PALMER, K. N. V., and SELLICK, B. A. (1953), Ibid., 1, 164. N

RINK, E. H. (1938), Proc. $R$. soc. Med., 31, ii, 1247.

ROVENSTINE, E. A. (1942), Curr. Res. Anesth., 21, 111.

SELLICK, B. A. (1952), Personal Communication.

SHORT, D. S. (1951), Quart. F. med., 20, 233.

STRINGER, P. (1947), Lancet, 1, 289.

SWANK, R. L., and SMEDEL, M. I. (1948), Amer. f. med., 5, $210 . ?$

THOMAS, C. P. (1938), Proc. R. soc. Med., 3I, ii, 1237. 